\title{
Information Sharing and Channel Construction of Supply Chain under Asymmetric Demand Information
}

\author{
Guangdong Wu, ${ }^{1}$ Qingshan Kong, ${ }^{2}$ Jian-gang Shi, ${ }^{2}$ Hamid Reza Karimi, ${ }^{3}$ and Wei Zhang ${ }^{4}$ \\ ${ }^{1}$ School of Tourism and Urban Management, Jiangxi University of Finance \& Economics, Nanchang 330013, China \\ ${ }^{2}$ School of Economics and Management, Tongji University, Shanghai 20009, China \\ ${ }^{3}$ Department of Engineering, Faculty of Engineering and Science, University of Agder, 4898 Grimstad, Norway \\ ${ }^{4}$ School of Management, Harbin Institute of Technology, Harbin, 150001, China \\ Correspondence should be addressed to Wei Zhang; hbue_wb@163.com
}

Received 1 March 2014; Accepted 19 March 2014; Published 14 April 2014

Academic Editor: M. Chadli

Copyright (C) 2014 Guangdong Wu et al. This is an open access article distributed under the Creative Commons Attribution License, which permits unrestricted use, distribution, and reproduction in any medium, provided the original work is properly cited.

\begin{abstract}
Information sharing and marketing channel building have become an important problem of supply chain management theory and practice. The research of information sharing focused on traditional channel of supply chain between upstream and downstream enterprises; however, the research ignores the behavior of information sharing with potential entrants and composite structure characteristics about traditional marketing channel with the direct channel. This paper uses the model to research the effects brought about sharing demand information with potential entrants and building marketing channel, which reveals information sharing and channel building mechanism in the supply chain. The study found that the five-force model of Porter regards potential entrants only as a threat that is one-sided. When the channel competitiveness meets certain conditions, manufacturer and retailer will share demand information with potential entrants. Building composite marketing channel is the manufacturer's absolute dominant strategy. Channel construction will increase the entry barriers for potential entrants and weaken the effect of double marginalization; meanwhile, the performance of supply chain will be augmented.
\end{abstract}

\section{Introduction}

Product demand information is of significance to enterprises. It is important for manufacturers and retailers to closely trace and predict demand information, thus forming the ability to deeply and exactly mine the demand information. Some state-of-the-art information technologies including UPC, POS, and EDI have been taken by manufacturers and retailers to acquire directly information on market demand from final clients and consumer purchasing behaviors. For instance, Apollo-Spaceman Co. Ltd. integrates demand information so as to make the whole decision. And Huawei Co. Ltd, by developing eLTE and GSM-R solutions and studying clients' demand, put forward a wireless solution that helps enterprises gain demand information and thus promotes their operation efficiency.

If potential entrants want to step into the market, they must get demand information in advance. The question is whether manufacturers and retailers will share demand information with them. Michael Porter's five forces mode simply sees potential entrants as threats. Darrough (1993) and Raith (1996) found that demand information sharing makes more potential entrants come into market and heat up competition $[1,2]$. Hwang and Kirby (2000) pointed out that sharing demand information could ease competition among existing enterprises but finally intensify competition since many potential entrants would land on market [3]. Dye (1986) and Park and Seo (2008) extend the research to study how the information sharing between enterprises with patents and those without would influence their competitive strategy [4, 5]. Berger (2011) and Beyer et al. (2010) indicated that existing enterprises tended to release as little demand information as possible to potential entrants to maintain their competitiveness $[6,7]$. The survey results conducted by Graham et al. (2005) showed that managers would not disclose demand information to avoid potential entrants' 
attention and competition increasing [8]. Guo et al. (2004) pointed out that enterprises with biotechnology patents cared little about demand information disclosure [9]. Both Karuna (2010) and $\mathrm{Li}$ (2010) found that potential entrants' entry into market would promote information sharing among enterprises $[10,11]$. The contradictory results of previous research make it necessary to study the information sharing strategy within supply chains with potential entrants [12-14].

Some literature also studied the information sharing strategy among supply chain enterprises, but few considered the situation with potential entrants. Tao et al. (2002) studied the information sharing strategy among enterprises in horizontal competition and found that retailers are more likely to share product cost information [15]. Chang and Jiang (2003), considering the different information sharing mode between a manufacturer and two different suppliers, indicated that information sharing could lower the uncertainty of the whole supply chain and boost the overall supply chain efficiency [16]. However, he added that suppliers would get no benefits if the cost of information sharing is too high. Tang et al. (2004) determined the optimized range of information sharing caused by different fixed ratio expense share based on traditional single channel marketing mode [17]. Zhang and Chen (2004), taking advantage of the signaling game model, studied the demand information sharing mechanism between manufacturers and retailers in traditional supply chains [18]. Yang et al. (2005) analyzed the condition for collecting uncertain demand information under traditional single channel supply chains and explained how they share the uncertain information given different situations [19]. Zhang et al. (2006) paid attention to the manufacturer's information sharing mechanism when it offered two different contracts within the framework of single manufacturer and single retailer and found that the prediction precision of demand information played an important role in the information sharing between upstream and downstream enterprises [20]. Chiang el al. (2003) noticed the important role of information sharing in promoting overall supply chain performance by studying a two-stage supply chain [21]. He pointed out that the good design of supply information sharing conditions and effective information sharing incentive mechanism could improve overall supply chain performance. Ai et al. (2008) constructed a double channel supply chain model and found that retailers are willing to share private forecasts only when market risk is under certain critical point [22]; meanwhile, manufacturers are inclined to accept information provided by retailers only when market risk exceeded another critical point higher than retailers' one, thus leading to a Nash equilibrium when market risk fell into certain range [2325]. It is obvious that, in sectors where market risk is small, manufacturers could gain dominant position without information sharing.

This paper constructed a two-layer double channel supply chain with potential entrants within an E-commerce framework. The game structure taken is three-stage decision succession where, first of all, manufacturers and retailers decide whether to share demand information and if potential entrants participate in market competition; then, upstream manufacturers choose marketing channel and price all the channels; at last, retailers and potential entrants determine retail price and sale volume. The results show that constructing double-channel supply chain is an absolutely dominant strategy for upstream manufacturers if they want to preserve dominant market position. By the help of doublechannel marketing network, they can get more profits, lift barriers against potential entrants, mitigate the effect of double marginalization, and avoid hurting the performance of supply chains by retailers thirst for benefits. It is a onesided view to simply see potential entrants as threats. In fact, when channels' competitiveness reaches certain point, manufacturers and retailers will choose to share information with potential entrants at the Pareto area where both sides' performance can be advanced. The results of this paper are obviously different from those of previous literature.

\section{Construction of Supply Chain Model}

Here we adopt the structural framework where two independent channels exist: retail channel and direct marketing channel controlled by manufacturers. Some assumptions are made as (1) the manufacturer $(M)$ sells products to the retailer $(R)$ by wholesale with price of $\omega$, and the retailer $(R)$ then sells products to the clients in price of $p_{r}$ and gets sales volume of $q_{r} ;(2)$ the manufacturer $(M)$ sold products directly to final clients with price of $p_{d}$ and gets sales volume of $q_{d} ;(3)$ there exists a potential entrant who needs early investment of $I$ and could get sales volume of $q_{e}$ with price of $p_{e}$ after entering the market. Then, a widely applied model could be properly set as follows:

$$
\begin{aligned}
& p_{d}=a-q_{d}-r q_{r}-e q_{e} \\
& p_{r}=a-q_{r}-r q_{d}-e q_{e} \\
& p_{e}=a-q_{e}-r q_{r}-r q_{d},
\end{aligned}
$$

where market capacity $a=a_{1}+a_{2}$, and as $\operatorname{Li}$ (2002) assumed [26], $a_{1}$ and $a_{2}$ follow independent and identical distribution $F\left(a_{i}\right) \sim\left(u_{i}, \sigma_{i}^{2}\right)$, where $a_{1} \in\left(\underline{a}_{1}, \bar{a}_{1}\right)$ is predicted demand made by manufacturers and retailers in the supply chain as their private information; $a_{2}$ represents the disturbance caused by the entry of potential entrants. Considering the homogenization of products, we set $r$ as existing channels' substitution rate for potential entrants and $e$ vice versa with $e \leq r$.

2.1. No Potential Entrant Scenario. The no potential entrant scenario just serves as a control to assess the impacts of information sharing on supply chain, where the sign of " $\widehat{N}$ " is used. In channel decision making, the traditional Stackelberg Game Succession is adopted, in which the information on market capacity is known to all, and manufacturers intervene market for higher benefits through setting prices for wholesales and direct marketing while retailers determine retail price only based on the competition caused by direct marketing. Under this no potential entrant scenario, the prices of wholesales and direct marketing are as follows:

$$
\widehat{p_{r}}=a-\widehat{q_{r}}-r \widehat{q_{d}} ; \quad \widehat{p_{d}}=a-\widehat{q_{d}}-r \widehat{q_{r}} .
$$


The profit function of retailers can be got by reducing cost of products purchased from their sales amount. The profit function of manufacturers, on the other hand, consists of profits gained by direct marketing and the wholesales to retailers, as indicated in the following:

$$
\begin{aligned}
& \max \widehat{\pi_{R}}=\widehat{p_{r}} \widehat{q_{r}}-\widehat{\omega} \widehat{q_{r}}=\left(a-\widehat{q_{r}}-r \widehat{q_{d}}\right) \widehat{q_{r}}-\widehat{\omega} \widehat{q_{r}} \\
& \max \widehat{\pi_{M}}=\widehat{p_{d}} \widehat{q_{d}}+\widehat{\omega} \widehat{q_{r}}=\left(a-\widehat{q_{d}}-r \widehat{q_{r}}\right) \widehat{q_{d}}+\widehat{\omega} \widehat{q_{r}} .
\end{aligned}
$$

By solving the first derivative of (3), retailers' optimal purchase and sales volumes as well as manufacturers' sales volumes through direct marketing are obtained:

$$
\widehat{q_{r}}=\frac{a}{r+2}-\frac{\widehat{w}}{2-r} ; \quad \widehat{q_{d}}=\frac{a}{r+2}+\frac{\widehat{w}}{2-r} .
$$

It can be found through basic analysis that retailers' sales volumes will decline as the wholesale price lifted up by upstream manufacturers who occupy that capacity by direct marketing. By setting wholesale price, manufacturers are able to maximize their profits and reach equilibrium at the wholesale price of $\widehat{w}=a(2-r) /\left(6-2 r^{2}-r\right)$. Substituting $\widehat{w}$ in (2) and (4), we got final prices and sales volumes:

$$
\begin{array}{lll}
\widehat{p_{r}}=\frac{a(4-3 r)}{6-2 r^{2}-r} ; & \widehat{p_{d}}=\frac{a(2-r)}{6-2 r^{2}-r} \\
\widehat{q_{r}}=\frac{2 a(1-r)}{6-2 r^{2}-r} ; & \widehat{q_{d}}=\frac{2 a(2-r)}{6-2 r^{2}-r} .
\end{array}
$$

Since retailers play a secondary role in the downstream of supply chains, their market capacity must be smaller than that of manufacturers' through direct marketing; that is, $\widehat{q_{r}}<$ $\widehat{q_{d}}$. The wholesale price should be equal to direct marketing, that is, $\widehat{w}=\widehat{p_{d}}$, lest retailers purchase products by direct marketing channels and disturb manufacturers' marketing channels. When we substitute the prices and sales volumes of both retailers and potential entrants in profit functions above, the maximum profits of retailers and manufacturers can be acquired, as shown in the following:

$$
\begin{gathered}
\max \widehat{\pi_{R}}=\frac{4 a^{2}(1-r)^{2}}{\left(2 r^{2}+r-6\right)^{2}} ; \\
\max \widehat{\pi_{M}}=\frac{2 a^{2}(2-r)}{(3-2 r)(r+2)^{2}} .
\end{gathered}
$$

\subsection{Single Channel Supply Chain with Potential Entrants.} In this scenario, we assume that there exists traditional retail channel and manufacturers did not sell products by direct marketing. In channel decision making, the traditional Stackelberg Game Succession is adopted, in which upstream manufacturers set wholesale price and retailers sell products to final consumers by retail price. At the same time, potential entrants can get demand information and take part in market competition. Here the sign of " $\widehat{N}$ " is used and the prices of retailers and potential entrants are shown as follows:

$$
\widetilde{p_{r}}=a-\widetilde{q_{r}}-e \widetilde{q_{e}} ; \quad \widetilde{p_{e}}=a-\widetilde{q_{e}}-r \widetilde{q_{r}} .
$$

Retailers' profits can be gotten by reducing cost of products purchased from their sales amount; that is, $\max \widetilde{\pi_{R}}=$ $\widetilde{p_{r}} \widetilde{q_{r}}-\widetilde{\omega} \widetilde{q_{r}}$; potential entrants' profits are the difference between their sales amount and early investment, that is, $\max \widetilde{\pi_{E}}=\widetilde{p_{e}} \widetilde{q_{e}}-I$. Through the first derivative method, we got the sales volumes of retailers and potential entrants as follows:

$$
\widetilde{q_{r}}=\frac{2 a-2 w-a e}{4-e r} ; \quad \widetilde{q_{e}}=\frac{2 a-a r+r w}{4-e r} .
$$

It can be found that retailers' sales volumes will decline as the wholesale price goes up while potential entrants can make up higher sales volumes. Manufacturers' profits come from wholesales to downstream retailers, that is, $\max \widetilde{\pi_{M}}=\widetilde{\omega} \widetilde{q_{r}}$, where the equilibrium wholesale price is $\widetilde{\omega}=(2 a-a e) / 4$. Then, we obtain the final price and sales volumes as follows:

$$
\begin{gathered}
\widetilde{p_{r}}=\frac{a(6-e r)(2-e)}{16-4 e r} ; \quad \widetilde{p_{e}}=\frac{a}{4}+\frac{a(2-r)}{8-2 e r} \\
\widetilde{q_{r}}=\frac{2 a-a e}{2(4-e r)} ; \quad \widetilde{q_{e}}=\frac{8 a-a e r-2 a r}{4(4-e r)} .
\end{gathered}
$$

Within single channel supply chain, manufacturers should consider the substitution rate of potential entrants' products when setting wholesale price. Retailers' market capacity is positively correlated with their channel competitiveness " $r$ " and negatively correlated with potential entrants" substitution rate " $e$." Substituting prices and sales volumes of retailers and potential entrants into their profit functions and the final profits of all participants can be gained:

$$
\begin{gathered}
\widetilde{\pi_{R}}=\frac{a^{2}(2-e)^{2}}{4(4-e r)^{2}} ; \quad \widetilde{\pi_{M}}=\frac{a^{2}(2-e)^{2}}{32-8 e r} ; \\
\widetilde{\pi_{E}}=a^{2}\left[\frac{8-2 r-e r}{4(4-e r)}\right]^{2}-I .
\end{gathered}
$$

Potential entrants decide whether they step into market based on their expected revenue. According to (10), their expected revenue $E_{a \mid a_{1}}\left\{a^{2}[\nu(r, e)]^{2}-I\right\}=\left[\left(a_{1}+u_{2}\right)^{2}+\right.$ $\left.\sigma_{2}^{2}\right][\nu(r, e)]^{2}-I$, where $\nu(r, e)=(8-2 r-e r) / 4(4-e r)$. So, if potential is informed of the demand bigger than $a_{1}^{+}=$ $\sqrt{\left(I /[\nu(r, e)]^{2}\right)-\sigma_{2}^{2}}-u_{2}$, they will choose to land on market.

2.3. Double-Channel Supply Chain with Potential Entrants. Here we consider a double-channel supply chain with potential entrants where manufacturers construct mixed supply chains consisting of wholesale channels and direct marketing channels, and potential entrants will participate in market competition after getting demand information. Under this scenario, prices of all sides are as follows:

$$
\begin{aligned}
& p_{d}=a-q_{d}-r q_{r}-e q_{e} \\
& p_{r}=a-q_{r}-r q_{d}-e q_{e} \\
& p_{e}=a-q_{e}-r q_{r}-r q_{d} .
\end{aligned}
$$

The profit function of manufacturers consists of profits gained by direct marketing and the wholesales to retailers, 
that is, $\max \pi_{M}=p_{d} q_{d}+\omega q_{r}=\left(a-q_{d}-r q_{r}-e q_{e}\right) q_{d}+$ $\omega q_{r}$. Retailers' profit function can be acquired by reducing cost of products purchased from their sales amount; that is, $\max \pi_{R}=p_{r} q_{r}-\omega q_{r}=\left(a-q_{r}-r q_{d}-e q_{e}\right) q_{r}-\omega q_{r}$. Potential entrants' profits are the difference between their sales amount and early investment; that is, $\max \pi_{E}=p_{e} q_{e}-I=\left(a-q_{e}-\right.$ $\left.r q_{r}-r q_{d}\right) q_{e}-I$. By solving the first derivative of combined equations, we got sales volumes of all participants:

$$
\begin{gathered}
q_{r}=\frac{2 a-w-a e}{2(r(1-e)+2)}-\frac{w}{2(2-r)} ; \\
q_{d}=\frac{2 a-w-a e}{2(r(1-e)+2)}+\frac{w}{2(2-r)} ; \\
q_{e}=\frac{2 a-a r+r w}{2(r(1-e)+2)} .
\end{gathered}
$$

From (12) we can see that retailers will sell fewer products with wholesale price going up and sales volumes of direct marketing and potential entrants will expand, which meant that the latter two sides will gain more sales volumes due to wholesale price increase. Manufacturers will set a wholesale price that maximizes their revenue. According to the profit function $\max \pi_{M}(\omega)=p_{d} q_{d}+\omega q_{r}=\left(a-q_{d}-r q_{r}-e q_{e}\right) q_{d}+\omega q_{r}$, the optimal wholesale price will be $\omega=2 A a(2-e)(2-r)(2 r-$ $\left.3 e r+e r^{2}-r^{2}+4\right)$, where $A=1 /\left[2 r^{3}\left(2 e-2 e^{2}\right)-48 e r+2 r^{2}\left(3 e^{2}+\right.\right.$ $12 e-12)+64]$. Substituting the solved $\omega$ in profit functions, we obtain all sides maximum profits:

$$
\begin{gathered}
\max \pi_{M}\left(q_{d}\right)=\frac{A a^{2}(2-e)^{2}(2-r)(6-r)}{2} \\
\max \pi_{R}\left(q_{r}\right)=A^{2} a^{2}(2-e)^{2}\left(e r^{2}-8 r+8\right)^{2} \\
\max \pi_{E}\left(q_{e}\right)=A^{2} a^{2}(2-r)^{4}(2 r-3 e r+8)^{2}-I .
\end{gathered}
$$

Similarly, potential entrants will take into account expected revenue so as to decide whether they come into market or not. Their expected revenue is $E_{a \mid a_{1}}\left\{a^{2}[\varphi(r, e)]^{2}-\right.$ $I\}=\left[\left(a_{1}+u_{2}\right)^{2}+\sigma_{2}{ }^{2}\right][\varphi(r, e)]^{2}-I$, where $\varphi(r, e)=$ $A(2-r)^{2}(2 r-3 e r+8)$. So, if potential got the information of $\left[\left(a_{1}+u_{2}\right)^{2}+\sigma_{2}{ }^{2}\right][\varphi(r, e)]^{2}-I>0$, where $a_{1}^{*}=$ $\sqrt{\left(I /[\varphi(r, e)]^{2}\right)-\sigma_{2}^{2}}-u_{2}$, they will step into market.

\section{Channel Choosing}

Results of single-channel and double-channel supply chains with potential entrants can be seen in Table 1. This section compares the results and analyzes upstream manufacturers' channel choosing strategy.

By comparing results of single-channel and doublechannel supply chains with potential entrants, we can get the following conclusions.

Proposition 1. The construction of double-channel supply chains can weaken the effect of double marginalization:

(1) the construction of double-channel supply chains can lower prices of retailers and potential entrants; that is, $p_{r}<\widetilde{p_{r}} ; p_{e}<\widetilde{p_{e}}$
(2) when $r<1-(e / 2(1-e))$, manufacturers will lower wholesale prices; that is, $\omega<\widetilde{\omega}$.

In traditional single-channel supply chains, upstream manufacturers tend to raise wholesale prices to get more profits and downstream retailers will lift retail prices as well to ensure their profits. The twofold price rise will hurt the overall supply chain performance considerably, which is called effect of double marginalization (Chiang et al., 2003). If upstream manufacturers construct double-channel supply chains and sell products through direct marketing in addition to wholesales, the situation of prices being added twice can be avoided and prices of potential entrants will also been lowered. Whether upstream manufacturers will lower wholesale prices depends on market's recognition of manufacturers' channels and potential entry channels. If product substitution rate follows $r>1-e /[2(1-e)]$, manufacturers will lift wholesale prices.

Proposition 2. The construction of double-channel supply chains will reduce the market capacity of retailers and potential entrants; that is, $q_{r}<\widetilde{q_{r}} ; q_{e}<\widetilde{q_{e}}$.

If upstream manufacturers adopt direct marketing, competition will be intensified with market capacity of retailers and potential entrants being occupied by manufacturers. Taking advantage of channels, manufacturers are able to take more market capacity and thus capacity of retailers and potential entrants will shrink.

Proposition 3. (1) The construction of double-channel supply chains will enlarge manufacturers' profits but reduce those of retailers and potential entrants.

(2) The construction of double-channel supply chains will boost the whole supply chain's profits and improve the overall supply chain performance.

Manufacturers' direct marketing channels will lower prices and sales volumes of both retailers and potential entrants, thus squeezing their profits. On the other hand, by constructing double-channel supply chains, manufacturers can expand their sales volumes, making the construction of double-channel supply chains their absolutely dominant strategy.

Proposition 4. Market barriers will be raised due to the construction of double-channel supply chains; that is, $a_{1}^{*}>a_{1}^{+}$.

In single-channel and double-channel supply chains with potential entrants, potential entrants choose stepping into market if market capacity follows $a_{1}>a_{1}^{*}=$ $\sqrt{\left(I /[\varphi(r, e)]^{2}\right)-\sigma_{2}^{2}}-u_{2}, a_{1}>a_{1}^{+}=\sqrt{\left(I /[\nu(r, e)]^{2}\right)-\sigma_{2}^{2}}-$ $u_{2}$. That market capacity is called market barriers against potential entrants. Manufacturers' direct marketing channels advance the existing supply chains' efficiency and promote supply chains' competitiveness. The construction of direct marketing channels raises market barriers against potential entrants, thus effectively protecting manufacturers' market position. If upstream manufacturers want to preserve their 
TABLE 1: Comparison results between single-channel and double-channel supply chains.

\begin{tabular}{cccc}
\hline & Double-channel supply chains & Relationship & Single-channel supply chains \\
\hline$p_{r}$ & $A a(2-e)\left(24-8 r-12 e r+11 e r^{2}-2 e r^{3}-8 r^{2}+2 r^{3}\right)$ & $<$ & $\frac{a(6-e r)(2-e)}{16-4 e r}$ \\
$p_{d}$ & $A a(2-e)(2-r)(2 r-3 e r+8)$ & $/$ & $/$ \\
$p_{e}$ & $A a(2-r)^{2}(2 r-3 e r+8)$ & $<$ & $\frac{a}{4}+\frac{a(2-r)}{8-2 e r}$ \\
$\omega$ & $2 A a(2-e)(2-r)\left(2 r-3 e r+e r^{2}-r^{2}+4\right)$ & & $\frac{2 a-a e}{2 a-a e}$ \\
$q_{r}$ & $A a(2-e)\left(e r^{2}-8 r+8\right)$ & $<$ & $/$ \\
$q_{d}$ & $A a(2-e)(2-r)(2 r-3 e r+8)$ & $<$ & $\frac{8 a-a e r-2 a r}{4(4-e r)}$ \\
$q_{e}$ & $A a(2-r)^{2}(2 r-3 e r+8)$ & $<$ & $\frac{a^{2}(2-e)^{2}}{32-8 e r}$ \\
$\pi_{M}$ & $\frac{A a^{2}(2-e)^{2}(2-r)(6-r)}{2}$ & $<$ & $\frac{a^{2}(2-e)^{2}}{4(4-e r)^{2}}$ \\
$\pi_{R}$ & $A^{2} a^{2}(2-e)^{2}\left(e r^{2}-8 r+8\right)^{2}$ & $<$ & $a^{2}\left[\frac{8-2 r-e r}{4(4-e r)}\right]^{2}-I$ \\
$\pi_{E}$ & $A^{2} a^{2}(r-2)^{4}(2 r-3 e r+8)^{2}-I$ & $<$ & \\
\hline
\end{tabular}

dominant market position, constructing double-channel supply chains is an absolutely dominant strategy.

\section{Information Sharing}

Market participants share asymmetric information on demand. Manufacturers and retailers are able to acquire exact demand information because they directly connect with final consumers. However, potential entrants cannot predict market capacity, which makes it necessary for them to ask for information from manufacturers or retailers if they want to come into market. Whether manufacturers and retailers will share demand information with potential entrants or not is the discussion center of this section. To facilitate the analysis of impacts of information sharing of manufacturers and retailers, here we set two scenarios: manufacturers sharing information only and retailers sharing information only.

(1) If retailers choose to share demand information with potential entrants, their expected revenue includes two parts:

(a) profits from potential entrants who join market after getting demand information;

(b) profits due to potential entrants' choice of not joining market since demand capacity cannot ensure their profits.

Retailers' expected revenue is indicated as follows:

$$
\begin{aligned}
& E\left(\pi_{R}\right) \\
& =\int_{\underline{a}_{1}}^{a^{*}}\left\{E_{a \mid a_{1}}\left[\left(a-\widehat{q_{r}}-r \widehat{q_{d}}\right) \widehat{q_{r}}-\widehat{\omega} \widehat{q_{r}}\right]\right\} d F\left(a_{1}\right) \\
& \quad+\int_{a^{*}}^{\bar{a}_{1}}\left\{E_{a \mid a_{1}}\left[\left(a-q_{r}-d q_{d}-e q_{e}\right) q_{r}-\omega q_{r}\right]\right\} d F\left(a_{1}\right)
\end{aligned}
$$

$$
\begin{gathered}
=\int_{\underline{a}_{1}}^{a^{*}}\left\{\frac{\left[\left(a_{1}+\mu_{2}\right)^{2}+\sigma_{2}^{2}\right]^{2} 4(1-r)^{2}}{\left(2 r^{2}+r-6\right)^{2}}\right\} d F\left(a_{1}\right) \\
+\int_{a^{*}}^{\bar{a}_{1}}\left\{\left[\left(a_{1}+\mu_{2}\right)^{2}+\sigma_{2}^{2}\right]^{2} A^{2}(2-e)^{2}\right. \\
\left.\times\left(e r^{2}-8 r+8\right)^{2}\right\} d F\left(a_{1}\right) .
\end{gathered}
$$

If retailers choose to not share information, potential entrants will not step into market because of lack of information. With the optimal prices and market capacity mentioned in Section 2.1, we can get retailers' expected revenue as follows:

$$
\begin{aligned}
E\left(\widehat{\pi_{R}}\right) & =\int_{\underline{a}_{1}}^{\bar{a}_{1}}\left\{E_{a \mid a_{1}}\left[\left(a-\widehat{q_{r}}-r \widehat{q_{d}}\right) \widehat{q_{r}}-\widehat{\omega} \widehat{q_{r}}\right]\right\} d F\left(a_{1}\right) \\
& =\int_{\underline{a}_{1}}^{\bar{a}_{1}}\left[\frac{\left[\left(a_{1}+\mu_{2}\right)^{2}+\sigma_{2}^{2}\right]^{2} 4(1-r)^{2}}{\left(2 r^{2}+r-6\right)^{2}}\right] d F\left(a_{1}\right) .
\end{aligned}
$$

If retailers' expected revenue increases after their demand information sharing, the following must be fulfilled:

$$
\begin{aligned}
& E\left(\pi_{R}\right)-E\left(\widehat{\pi_{R}}\right) \\
&=\int_{a^{*}}^{\bar{a}_{1}}\left\{\left[\left(a_{1}+\mu_{2}\right)^{2}+\sigma_{2}^{2}\right]^{2} A^{2}(2-e)^{2}\right. \\
&\left.\quad \times\left(e r^{2}-8 r+8\right)^{2}\right\} d F\left(a_{1}\right)
\end{aligned}
$$




$$
\begin{aligned}
& -\int_{a^{*}}^{\bar{a}_{1}}\left[\frac{\left[\left(a_{1}+\mu_{2}\right)^{2}+\sigma_{2}^{2}\right]^{2} 4(1-r)^{2}}{\left(2 r^{2}+r-6\right)^{2}}\right] d F\left(a_{1}\right)>0 \\
& \Longrightarrow A(2-e)\left(e r^{2}-8 r+8\right)-\frac{2(1-r)}{\left(2 r^{2}+r-6\right)}>0 .
\end{aligned}
$$

(2) If manufacturers choose to share demand information with potential entrants, their expected revenue includes two parts:

(a) profits from potential entrants who join market after getting demand information;

(b) profits due to potential entrants' choice of not joining market since demand capacity cannot ensure their profits.

Manufacturers' expected revenue is indicated as follows:

$$
\begin{aligned}
& E\left(\pi_{M}\right) \\
& =\int_{\underline{a}_{1}}^{a^{*}}\left\{E_{a \mid a_{1}}\left[\widehat{p_{d}} \widehat{q_{d}}+\widehat{\omega} \widehat{q_{r}}\right]\right\} d F\left(a_{1}\right) \\
& \quad+\int_{a^{*}}^{\bar{a}_{1}}\left\{E_{a \mid a_{1}}\left[p_{d} q_{d}+\omega q_{r}\right]\right\} d F\left(a_{1}\right) \\
& =\int_{\underline{a}_{1}}^{a^{*}}\left\{\frac{2\left[\left(a_{1}+\mu_{2}\right)^{2}+\sigma_{2}^{2}\right]^{2}(2-r)}{(3-2 r)(r+2)^{2}}\right\} d F\left(a_{1}\right) \\
& \quad+\int_{a^{*}}^{\bar{a}_{1}}\left\{\frac{A\left[\left(a_{1}+\mu_{2}\right)^{2}+\sigma_{2}^{2}\right]^{2}(2-e)^{2}(2-r)(6-r)}{2}\right\} d F\left(a_{1}\right) .
\end{aligned}
$$

If manufacturers choose not to share demand information with potential entrants, their expected revenue is

$$
\begin{aligned}
E\left(\widehat{\pi_{M}}\right) & =\int_{\underline{a}_{1}}^{\overline{a_{1}}}\left\{E_{a \mid a_{1}}\left[\widehat{p_{d}} \widehat{q_{d}}+\widehat{\omega} \widehat{q_{r}}\right]\right\} d F\left(a_{1}\right) \\
& =\int_{\underline{a}_{1}}^{\bar{a}_{1}}\left\{\frac{2\left[\left(a_{1}+\mu_{2}\right)^{2}+\sigma_{2}^{2}\right]^{2}(2-r)}{(3-2 r)(r+2)^{2}}\right\} d F\left(a_{1}\right) .
\end{aligned}
$$

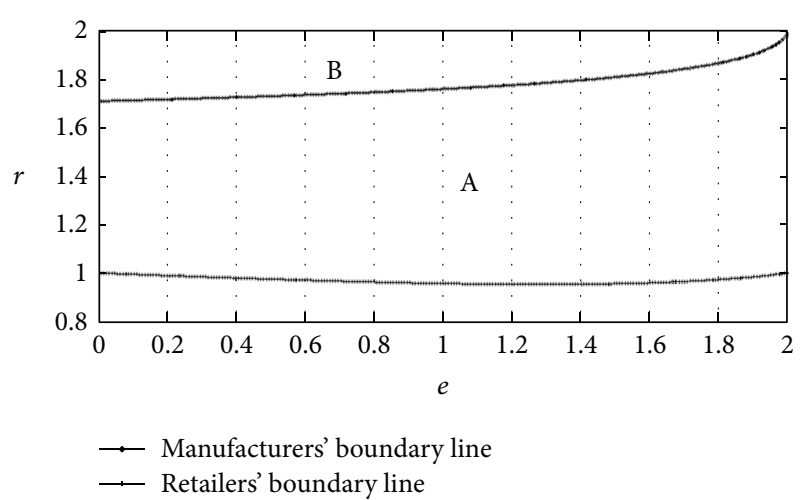

FIGURE 1: Information sharing range.

If manufacturers' expected revenue increases after their demand information sharing, the following must be fulfilled:

$$
\begin{aligned}
& E\left(\pi_{M}\right)-E\left(\widehat{\pi_{M}}\right) \\
& =\int_{a^{*}}^{\bar{a}_{1}}\left\{\frac{A\left[\left(a_{1}+\mu_{2}\right)^{2}+\sigma_{2}^{2}\right]^{2}(2-e)^{2}(2-r)(6-r)}{2}\right\} d F\left(a_{1}\right) \\
& \quad-\int_{a^{*}}^{\bar{a}_{1}}\left\{\frac{2\left[\left(a_{1}+\mu_{2}\right)^{2}+\sigma_{2}^{2}\right]^{2}(2-r)}{(3-2 r)(r+2)^{2}}\right\} d F\left(a_{1}\right)>0 \\
& \Longrightarrow \frac{A(2-e)^{2}(2-r)(6-r)}{2}-\frac{2(2-r)}{(3-2 r)(r+2)^{2}}>0 .
\end{aligned}
$$

According to the results above, we can map the boundary line where manufactures and retailers choose to share information (Figure 1).

Proposition 5. In area $A$, retailers can get more profits by sharing demand information with potential entrants but lower manufacturers' profits. There exists Pareto area $B$ where both manufacturers and retailers can increase profits by sharing demand information.

Whether retailers and producers will share demand information with potential entrants depends on the competitiveness of their channels. When market recognition of retail channel and potential entrants' sales channel meets certain conditions (area $A$ ), retailers will share market demand information with potential entrants, which is unprofitable to manufacturers. For area $B$, market recognition " $r$ " for retail channel and manufacturers' direct marketing channel is relatively high, so that both retailers and manufacturers will share market demand information with potential entrants, which validates that companies with biotechnology patent do not care if the market information is disclosed. When certain conditions are satisfied, it is beneficial to involve potential entrants into market competition. 


\section{Conclusion}

This paper constructed a double-channel supply chain model to study the effects brought about by sharing information with potential entrants and building marketing channel, revealing the mechanism of information sharing and channel building in the supply chain. The study found that building composite marketing channel is the manufacturer's absolute dominant strategy and that double-channel construction would raise profits, increase the entry barriers for potential entrants, weaken the effect of double marginalization, and avoid undermining the performance of supply chain for retailers' interests. The five force model of Porter regards potential entrants only as a threat that is one-sided. When the channel competitiveness meets certain conditions, manufacturer and retailers will share demand information with potential entrants. Pareto interval is presented, and sharing demand information with potential entrants is benefit for both retailers and producers. This result provides a theoretical basis for further research on the information sharing and channel building in the supply chain mechanism under the electronic commerce environment.

\section{Conflict of Interests}

The authors declare that there is no conflict of interests regarding the publication of this paper.

\section{Acknowledgments}

This work was supported by the National Natural Science Funds of China (Grant nos. 71273076, 71301065, and 71303271), the Humanities and Social Sciences Youth Foundation of Chinese Ministry of Education (Grant no. 3YJC630166), and the National Social Science Foundation of China (Grant no. 12CTQ029).

\section{References}

[1] M. Darrough, "Disclosure policy and competition: Cournot vs. Bertrand," The Accounting Review, vol. 68, no. 3, pp. 534-561, 1993.

[2] M. Raith, "A general model of information sharing in oligopoly," Journal of Economic Theory, vol. 71, no. 1, pp. 260-288, 1996.

[3] Y. Hwang and A. J. Kirby, "Competitive effects of disclosure in a strategic entry model," Review of Accounting Studies, vol. 5, no. 1, pp. 57-85, 2000.

[4] R. Dye, "Proprietary and nonproprietary disclosure," The Journal of Business, vol. 59, no. 2, pp. 331-366, 1986.

[5] J. Park and K. Seo, "Bundling, information aggregation and entry deterrence," Economics Letters, vol. 101, no. 2, pp. 100-102, 2008.

[6] P. G. Berger, "Challenges and opportunities in disclosure research-a discussion of 'the financial reporting environment: review of the recent literature," Journal of Accounting and Economics, vol. 51, no. 1-2, pp. 204-218, 2011.

[7] A. Beyer, D. A. Cohen, T. Z. Lys, and B. R. Walther, "The financial reporting environment: review of the recent literature," Journal of Accounting and Economics, vol. 50, no. 2-3, pp. 296$343,2010$.
[8] J. R. Graham, C. R. Harvey, and S. Rajgopal, "The economic implications of corporate financial reporting," Journal of Accounting and Economics, vol. 40, no. 1-3, pp. 3-73, 2005.

[9] R.-J. Guo, B. Lev, and N. Zhou, "Competitive costs of disclosure by biotech IPOs," Journal of Accounting Research, vol. 42, no. 2, pp. 319-355, 2004.

[10] C. Karuna, "Industry product market competition and corporate voluntary disclosure: evidence from forward-looking line items at the industrial segment level," Tech. Rep., University of Houston, 2010.

[11] X. Li, "The impacts of product market competition on the quantity and quality of voluntary disclosures," Review of Accounting Studies, vol. 15, no. 3, pp. 663-711, 2010.

[12] S. Yin, H. Luo, and S. Ding, "Real-time implementation of faulttolerant control systems with performance optimization," IEEE Transactions on Industrial Electronics, vol. 64, no. 5, pp. 24022411, 2014.

[13] S. Yin, G. Wang, and H. Karimi, "Data-drivendesign of robust fault detection system forwind turbines," Mechatronics. In press.

[14] S. Yin, S. X. Ding, A. H. A. Sari, and H. Hao, "Data-driven monitoring for stochastic systems and its application on batch process," International Journal of Systems Science. Principles and Applications of Systems and Integration, vol. 44, no. 7, pp. 13661376, 2013.

[15] W. Y. Tao, J. S. Kou, and M. Q. Li, "Effect of information sharing on supply chain," Journal of Systems Engineering, vol. 17, no. 6, pp. 486-490, 2002.

[16] Z. P. Chang and F. Jiang, "The study on optimal scope of information sharing under the condition of fixd fraction cost sharing," Journal of Industrial Engineering/Engineering Management, vol. 17, no. 4, pp. 473-475, 2003.

[17] H. X. Tang, J. M. He, and C. L. Liu, "Supply chain information sharing mechanism under the condition of asymmetric demand information," Journal of Systems Engineering, vol. 19, no. 6, pp. 589-595, 2004.

[18] Y. L. Zhang and J. Chen, "Study based on stackelberg game about the information sharing coordination in supply chain," Journal of Industrial Engineering/Engineering Management, vol. 18, no. 3, pp. 118-120, 2004.

[19] B. Yang, X. W. Tang, and X. Z. Ai, "Study on the information sharing performance based on the vertical monopolization," Chinese Journal of Management Science, vol. 13, no. 1, pp. 76-81, 2005.

[20] X. F. Zhang, Y. Zhao, and G. H. Xu, "Study on managerial incentive of information sharing in supply chain," Journal of Industrial Engineering/Engineering Management, vol. 20, no. 2, pp. 123-125, 2006.

[21] W.-Y. K. Chiang, D. Chhajed, and J. D. Hess, "Direct marketing, indirect profits: a strategic analysis of dual-channel supplychain design," Management Science, vol. 49, no. 1, pp. 1-20, 2003.

[22] X. Z. Ai, X. W. Tang, and Y. K. Ma, "Performance of forecasting information sharing between traditional channel and Echannel," Journal of Management Science in China, vol. 11, no. 1, pp. 12-21, 2008.

[23] S. Yin, S. Ding, A. Haghani, H. Hao, and P. Zhang, "A comparison study of basic data driven fault diagnosis and process monitoring methods on the benchmark Tennessee Eastman process," Journal of Process Control, vol. 22, no. 9, pp. 1567-1581, 2012.

[24] S. Yin, X. Yang, and H. R. Karimi, "Data-driven adaptive observer for fault diagnosis," Mathematical Problems in Engineering, vol. 2012, Article ID 832836, 21 pages, 2012. 
[25] W. Zhang, Q. Zhang, and H. Karimi, "Seeking the important nodes of complex networks in product R\&D team based on fuzzy AHP and TOPSIS," Mathematical Problems in Engineering, vol. 2013, Article ID 327592, 9 pages, 2013.

[26] L. Li, "Information sharing in a supply chain with horizontal competition," Management Science, vol. 48, no. 9, pp. 1196-1212, 2002. 


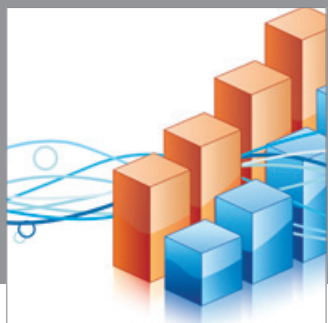

Advances in

Operations Research

mansans

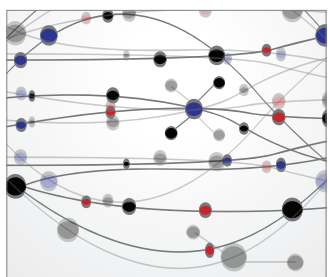

The Scientific World Journal
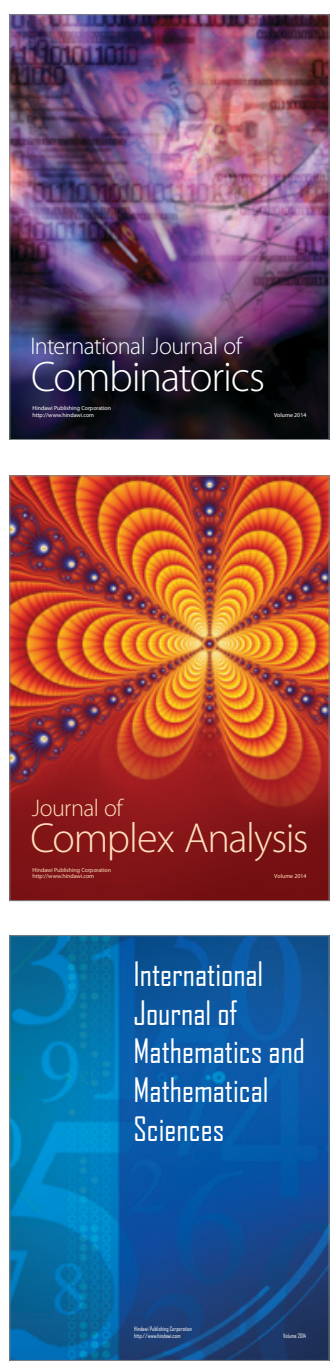
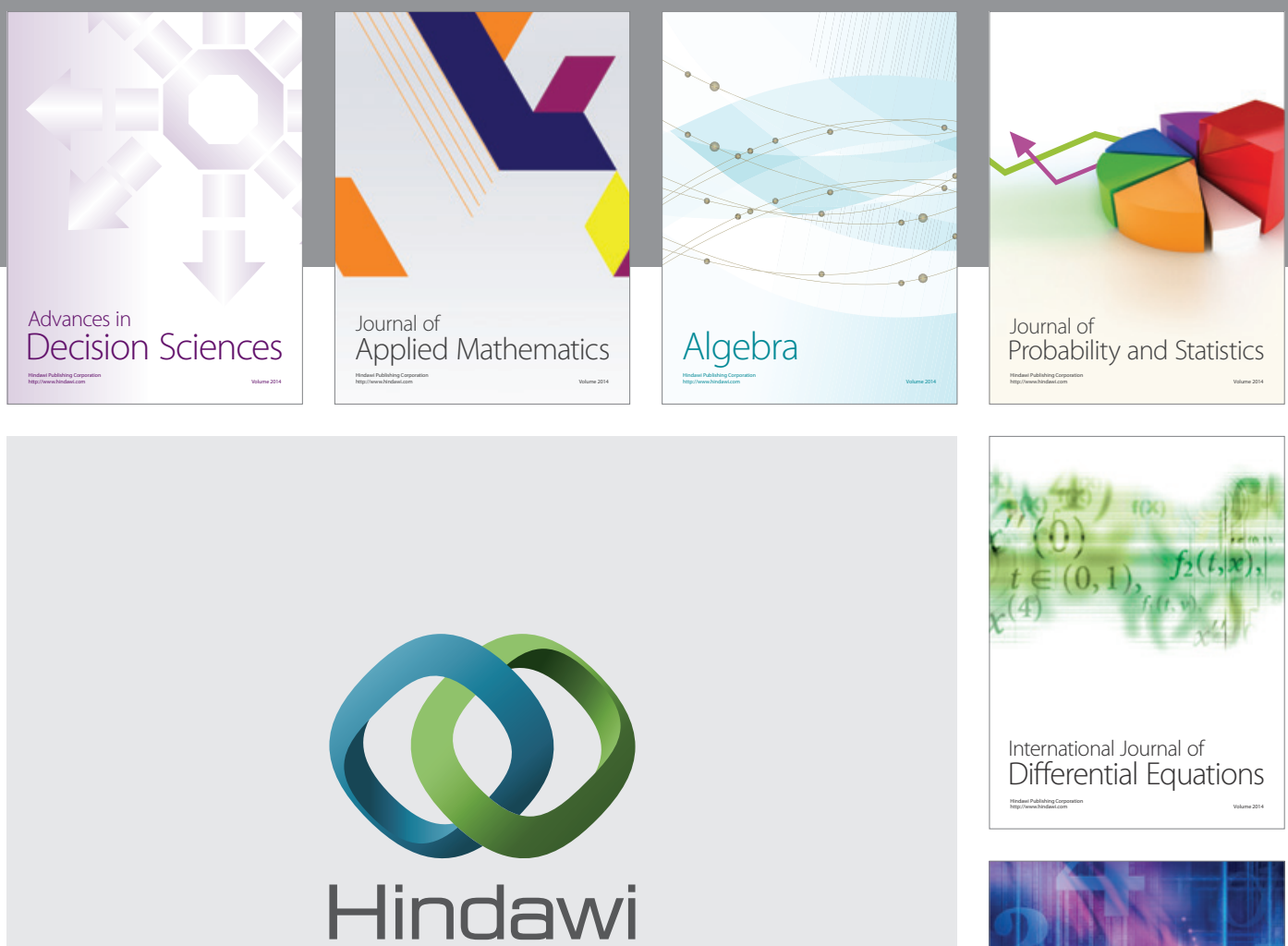

Submit your manuscripts at http://www.hindawi.com
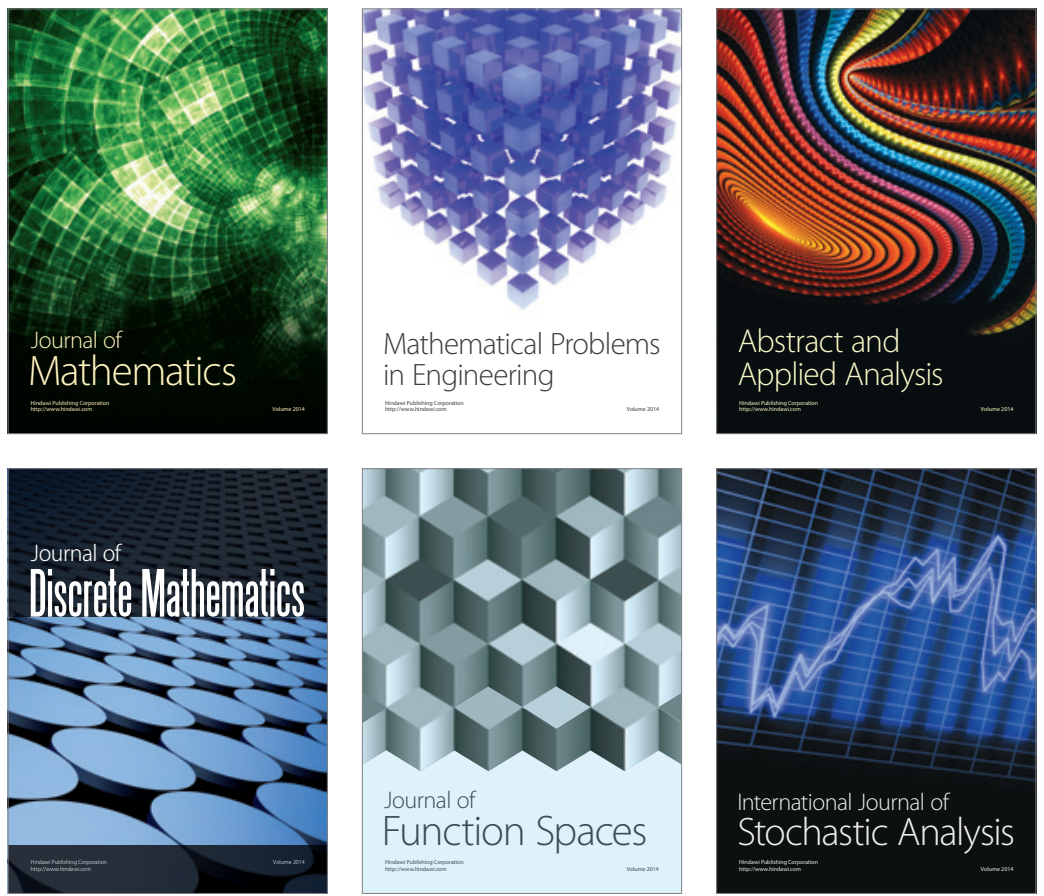

Journal of

Function Spaces

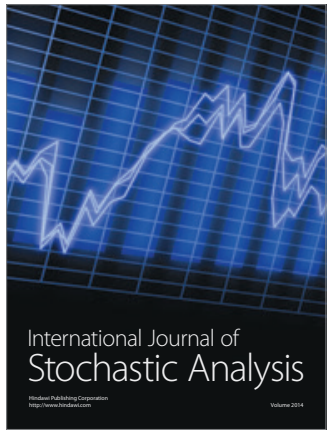

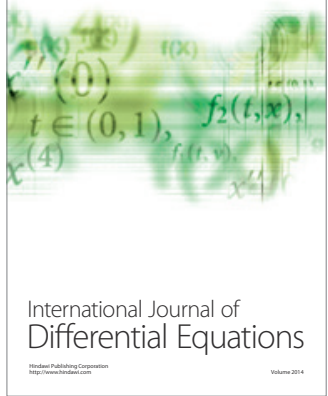
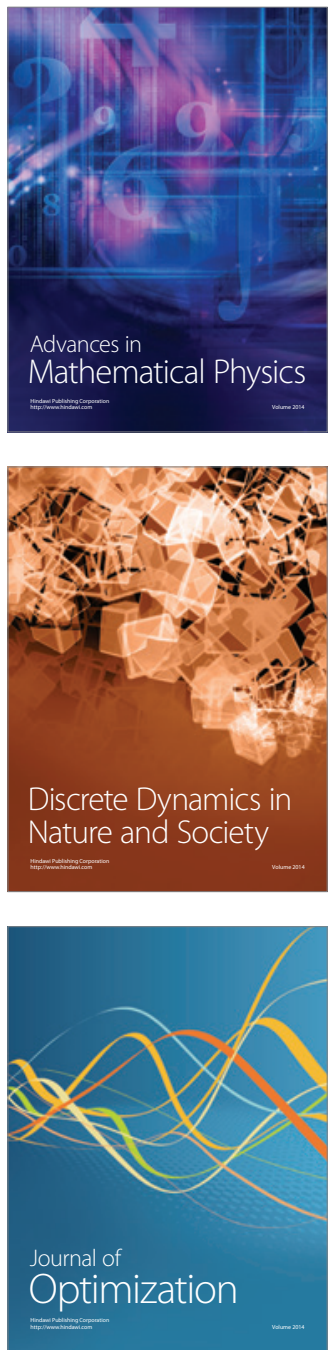